NIST

PUBLICATIONS

\title{
The Determination of Density of Mass Standards; Requirement and Method
}

Randall Schoonover

Mei-Sywe Hwang

Roland Nater

U.S. DEPARTMENT OF COMMERCE

Technology Administration

National Institute of Standards

and Technology

Gaithersburg, MD 20899 



\section{The Determination of Density of Mass Standards; Requirement and Method}

\section{Randall Schoonover Mei-Sywe Hwang Roland Nater}

U.S. DEPARTMENT OF COMMERCE Technology Administration National Institute of Standards and Technology

Gaithersburg, MD 20899

February 1994

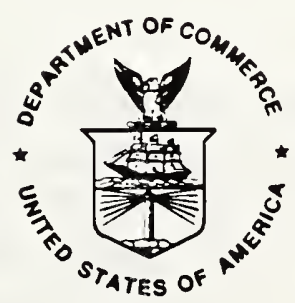

U.S. DEPARTMENT OF COMMERCE Ronald H. Brown, Secretary

TECHNOLOGY ADMINISTRATION Mary $L$ Good, Under Secretary for Technology

NATIONAL INSTITUTE OF STANDARDS AND TECHNOLOGY

Arati Prabhakar, Director 



\title{
The Determination of Density of Mass Standards; \\ Requirement and Method
}

\author{
Randall Schoonover, NIST \\ Gaithersburg, MD \\ Mei-Sywe Hwang, ITRI \\ Hsinchu, Taiwan \\ Roland Nater, Mettler-Toledo AG \\ Greifensee, Switzerland \\ KEYWORDS
}

Hydrostatic Weighing, Density Measurement, Electronic Balance, Mass, Laboratory Weights and Calibration.

\begin{abstract}
The usual method of a mass assignment to an artifact is. by comparing the forces exerted on a balance pan. The observed difference between the standard mass and the unknown object is then expressed as the solution of the two force equations which includes terms for their respective displacement volumes, i.e., densities. With the advent of commercially available balances with precision near the 1 part per billion (10\%) (ppb) level the user must pay particular attention to the artifact density and its associated error if the available precision is to be meaningful. Described here are the need and a method to determine the artifact density, and an error analysis that leads to the selection of the appropriate equipment. Measurements of a 200-g silicon crystal of known density were performed to demonstrate the accuracy of the method.
\end{abstract}

\section{INTRODUCTION}

Beginning in 1965, Bowman and Schoonover published a series of papers $[1,2,3,4,5]$ that described the use of the mechanical one-pan two-knife balance in the highprecision determination of the density of a solid object. That work demonstrated that density measurements could be made with a precision better than 1 part per million (ppm) [3]. In recent years the electronic force balance [6] has been perfected to a degree that it can replace most mechanical balances in both precision and capacity. Hence the mechanical balance is rapidly disappearing from the scene. In the following discussion we present the need for accurate knowledge of the artifact densities in a 
mass measurement and explore the use of the electronic balance to measure the density of laboratory weights or any solid object.

\section{REQUIREMENTS}

The solution equation for the mass comparison between two artifacts is:

$$
X=\left[S\left(1-\rho_{\mathrm{s}} / \rho_{\mathrm{s}}\right)-\mathrm{d}\right] /\left(1-\rho_{\mathrm{s}} / \rho_{\mathrm{x}}\right)
$$

where $S$ is the mass of the standard, $\rho$, its density, $\rho_{x}$ is the density of the mass $x$, $\rho$, the density of air, $d$ the difference observed on the balance and the remaining terms relate to the unknown mass. All terms have units that will result in the mass of $X$ in grams.

A rigorous error analysis [7] reveals the need to measure the density of the mass artifacts to 1 part in 100,000 if the associated error is not to exceed 1 part in 1 billion. This requirement is compatible with the precision of the best mass comparators in use today.

\section{PRINCIPLES AND APPLICATION}

There are several important gravimetric applications that can be performed on the electronic balance [8]. We have limited the discussion here to hydrostatic weighing principles and in particular the density determination of a solid object is discussed in simple form and later extended to a more general form. Related topics of liquid density and glassware volume are briefly mentioned in the appendix of this report. Mass measurement is not necessary in the course of a density determination, but is addressed in the deveiopment of the general method.

\section{The Density of a Solid by Hydrostatic Weighing.}

It was shown in the 1967 work [2] that one does not need to use a mass standard to measure the density of a solid object by hydrostatic weighing. The only requirements are knowledge of the densities of air and water, and availability of a linear gravimetric force scale. For completeness we present the development of the equation required for a solid object density determination when the object is suspended from a gravimetric force detector, first in air and then in water. We have chosen a simple but perfectly linear spring scale (force-balance) as our detector. To make this concept clear we begin with a special case where the temperature of the air, the water and the object are in mutual equilibrium. Furthermore, the air density and the spring constant of the detector remain unchanged throughout the measurement and the detector scale reads zero when the pan is empty both in air and in water. Figure 1 illustrates the four detector observations required to weigh an object in air and then in water. The following two equations are expressed in terms of the observables, the known and unknown components: 
AIR WEIGHING
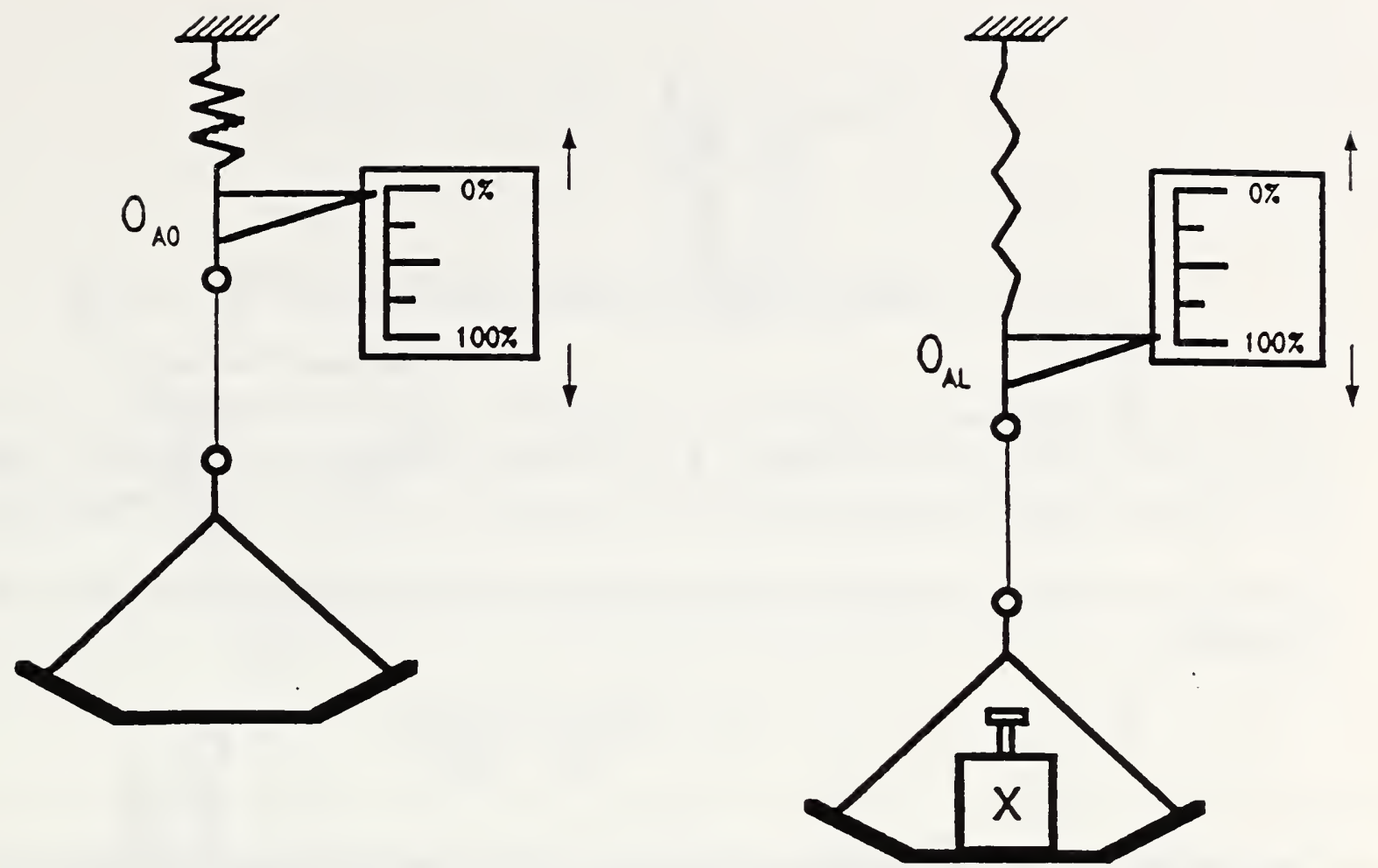

\section{WATER WEIGHING}
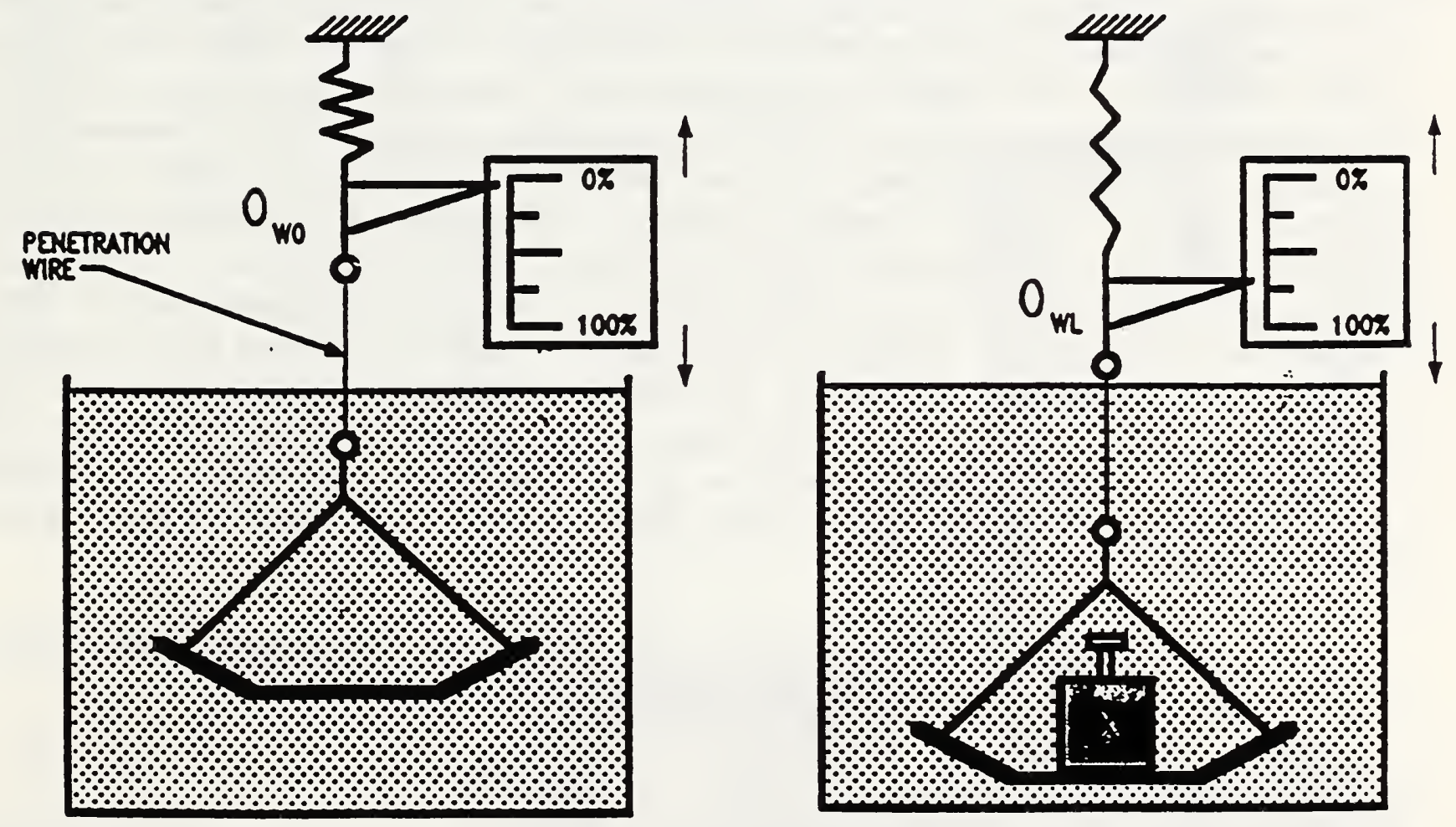

Figure 1. The spring balance is used to illustrate the principal of hydrostatic weighing. 


$$
\begin{gathered}
M_{x} g\left(1-\frac{\rho_{a}}{\rho_{x}}\right)=K O_{A L} \text { (air weighing) } \\
M_{x} g\left(1-\frac{\rho_{w}}{\rho_{x}}\right)=K O_{w L} \text { (water weighing) }
\end{gathered}
$$

where $M_{x}$ is the mass of object $X, \rho_{x}$ its density, $\rho_{0}$ is the air density, $\rho_{w}$ is the water density, $K$ is the spring constant, $g$ is the local acceleration of gravity, and $O_{A L}$ and $O_{m}$ are the detector observations when loaded in air and water respectively.

Solving the above equations for the density of object $X$, $\rho x$, one obtains the following equation:

$$
\rho_{x}=\frac{O_{w L} \rho_{s}-O_{A L} \rho_{w}}{O_{w L}-O_{A L}}
$$

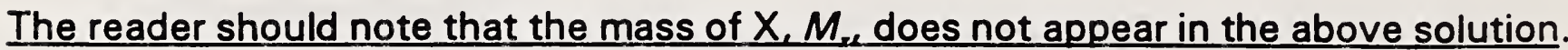

The difficulty associated with the use of eq. (3) is the required thermal equilibrium and the constant air density during the weighing cycles. Equilibrium is nearly impossible to achieve in practice and therefore it is desirable to have the water temperature cooler (by about $1^{\circ} \mathrm{C}$ ) than the surrounding air. Otherwise water vapor is driven to the cooler balance mechanism where it condenses causing a loss of measurement precision. However, equilibrium can be closely approximated in a stable laboratory environment. Air density changes are related to temperature, barometric pressure, relative humidity and carbon dioxide $\left(\mathrm{CO}_{2}\right)$ content. Normal laboratory $\mathrm{CO}_{2}$ variations and humidity excursions have a slight effect on air density and nature limits pressure variations to about $4 \%$. Climatic control systems readily maintain air temperature within $0.5^{\circ} \mathrm{C}$ or better. Therefore, air density variations are limited to about $10 \%$ and may be much less on an hourly basis. Although the equilibrium constraint is violated, the resultant errors may be acceptable to some users. To predict performance at the part per million level, a more general formulation is given later in the discussion.

A more detailed examination of these requirements is presented later. We reiterate that a mass standard is totally unnecessary for this measurement.

\section{THE FORCE DETECTOR}

Although not perfect like the imaginary spring-balance force detector described above, the performance of modern electronic force balance is nearly perfect for many purposes. An overview of these instruments is given in $[6,8]$. A short summary of the principles of operation is given here. Detailed knowledge of the electronic circuits is unnecessary. Figure 2 illustrates the basic principles of a force balance, and a 


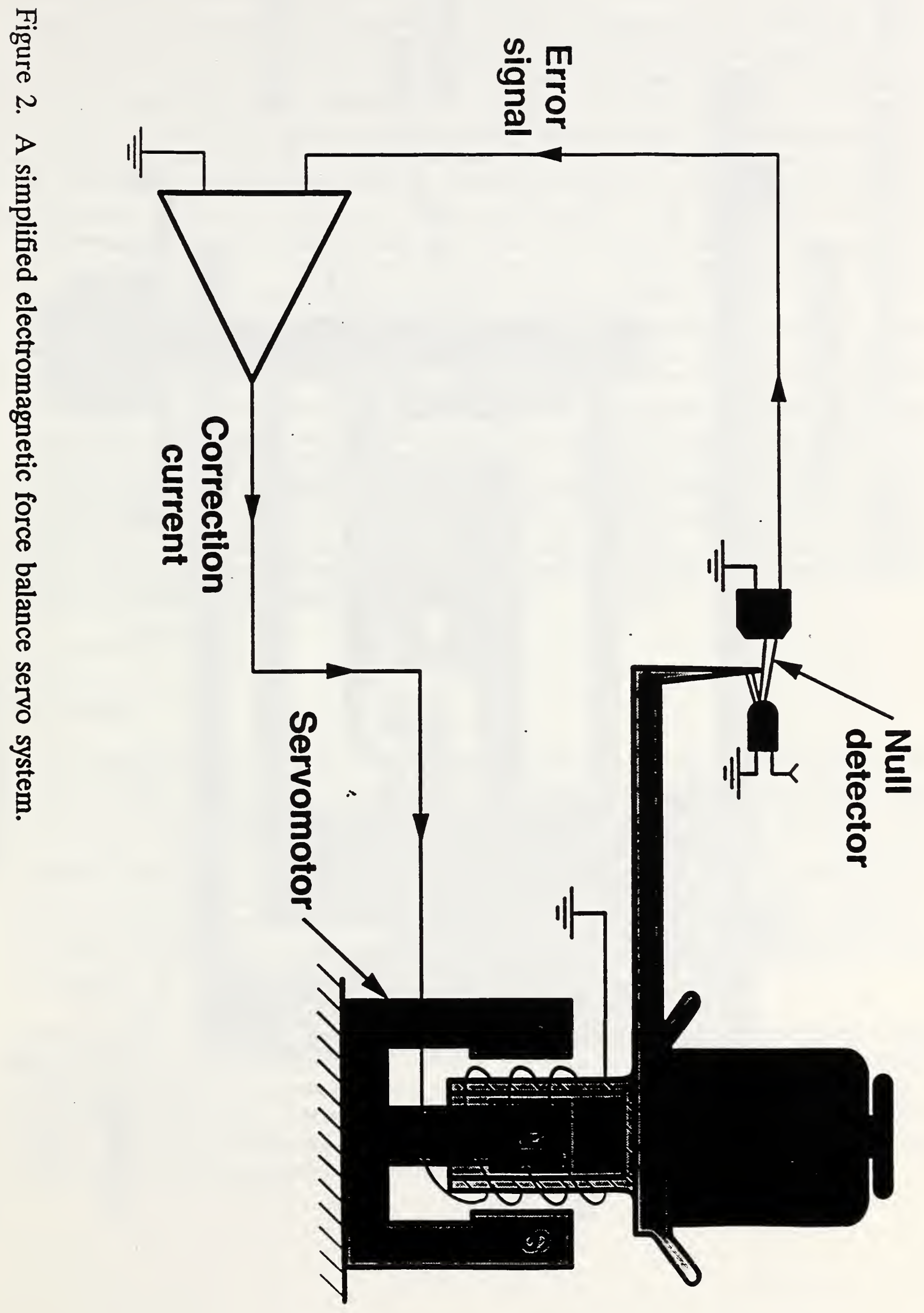


वृ

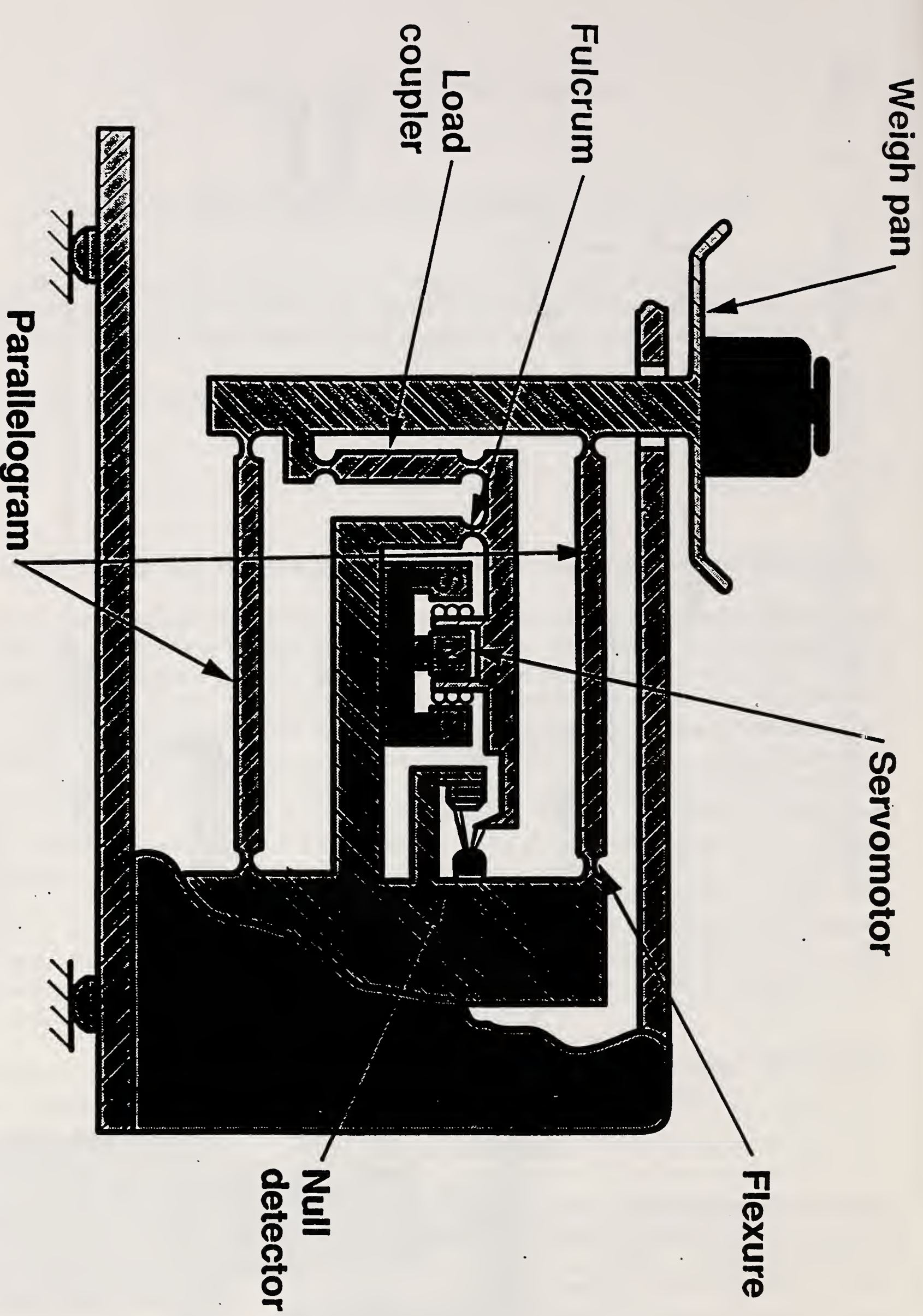


representative mechanical structure is shown in Fig. 3. When a downward force is applied to the balance pan (loaded with an object) it is opposed by a magnetic force generated by the interaction of two magnetic fields. One field is generated by a permanent magnet and the other a controllable electromagnet. Usually, the magnetic force is applied through a multiplying lever and not by direct levitation. Sufficient magnetic force is generated to restore the mechanism (pan) to its unloaded position, or null point, relative to its structure as determined by a position sensor. Obviously, the device is electromechanical and we should expect errors both random and systematic to arise in the use of these instruments. It is desirable in common weighing applications to tie the magnetic force to the unit of mass via calibration of the electronic circuit. The circuit is adjusted such that the algebraic sum of the gravitational and buoyant forces produces a balance indication approximately equal to the nominal value of the applied mass. It is common practice for high precision balances to be supplied with a mass standard whose density is about $8 \mathrm{~g} / \mathrm{cm}^{3}$ and with mass adjusted to a nominal value. This practice provides for a uniform response among balances to the given load at a given location. This mass and the high degree of precision and linearity of the electronic force balance eliminates the need for a calibrated set of mass standards (weight set). In pursuing the application of eq. (3) it is unnecessary to quantify the mass in terms of any unit definition nor do we care about its density; it is merely a convenient method to restore the spring constant if shifted from the initial value. However, when the calibration weight is tied to the mass unit the electronic balance provides a convenient way to multiply and divide the mass unit within the capacity of the instrument.

\section{Air Density}

The knowledge of the density of air and water embodies the information that ties the above density measurement to the SI units. In the interest of obtaining the highest accuracy, the best available formulas are used in calculating these parameters. The air density equation for moist air used in this work is the CIPM 1981/91 recommendation [9]. This formula ties its predecessor, CIPM-81, to the International Temperature Scale of 1990 (ITS-90) and utilizes better estimates for the values of some of the constants and other parameters. For brevity we do not reproduce the formula here, but note that a 0.0004 mole fraction for $\mathrm{CO}_{2}$ is assumed in our laboratory.

Errors in value of the parameters temperature, pressure and relative humidity do affect the uncertainty of the calculated air density. These parameters are measured at NIST with well-calibrated instruments with respective errors of $0.01^{\circ} \mathrm{C}, 13$ pascals 0.1 $\mathrm{mm} \mathrm{Hg}$ ), and $2 \% \mathrm{RH}$. Based on these error estimates, an uncertainty of 0.0003 $\mathrm{mg} / \mathrm{cm}^{3}$ (1 S.D.) has been assigned to the calculated air density values. It is this error estimate that is propagated in the analysis presented later. 


\section{Water Density}

The work of Kell [10] is generally accepted as the best comprehensive treatment of water density. The Kell formula provides a value for the density of air-free water at 1 atmosphere of pressure with an estimated uncertainty of $5 \mathrm{ppm}$. The formula assumes the use of the IPTS-1968 (t68) temperature scale and temperatures measured in terms of the IPTS-1990 (t90) must be converted to IPTS-1968. This is readily accomplished in the range between $20^{\circ} \mathrm{C}$ and $30^{\circ} \mathrm{C}$ from the following approximate relationship [11]:

$$
\mathrm{t} 90-\mathrm{t} 68=-0.006{ }^{\circ} \mathrm{C}
$$

Values of density $\rho_{\text {ket }}$ obtained using Kell's formula may be adjusted for the effects of reaeration of the water after boiling, dissolved gases, and the compressibility of water using the correction terms developed by Bowman and Schoonover [2] which give improved values:

$$
\rho_{w}=\rho_{\text {Koll }}\left[\frac{1}{1-C\left[\frac{B}{760}+\frac{1}{1033}-1\right]}\right]\left[1-\left(2.11-0.053 t_{w}\right)\left(1-\frac{1}{1+D}\right)\right]\left(10^{-6}\right)
$$

Where:

$\rho_{w} \quad=$ water density

$t_{w}=$ water temperature

$D \quad=$ days since boiling

$C=$ compressibility $=47.7 \mathrm{ppm} / \mathrm{atm}$

I = immersed sample deptb, $\mathrm{cm}$

$B=$ barometric pressure, in $\mathrm{mm} \mathrm{Hg}$

$\rho_{\text {Ket }}=$ Kell's water density

We note that the originally-published formula and units have been retained. The water temperature measurements here are estimated to be uncertain by $0.003{ }^{\circ} \mathrm{C}$ with a negligible effect on the water density.

\section{A GENERAL ALGORITHM FOR HYDROSTATIC WEIGHING}

The equilibrium conditions imposed by the use of eq. (3) can be avoided with a more detailed algorithm. The chief advantage is the achievement of improved estimates of measurement uncertainty. With a little extra effort, higher performance can be obtained from the balance. Both topics go hand in hand and are presented together here. However, before proceeding it is beneficial to first examine the effects of nonlinear balance response in a simple mass measurement. 
In the above hydrostatic weighing derivation the balance response is discussed in terms of a spring constant and the product of mass and local gravity is used to adjust the constant. In effect, the balance response is calibrated in terms of the gravitational force less the buoyant force exerted on the balance. This force is expressed by the following equation:

$$
S\left(1-\frac{\rho_{a}}{\rho_{s t}}\right) g=K O_{1 a}
$$

where $S$ is the mass of the calibration weight and $\rho_{s t}$ its density at temperature t.

The force imposed on the balance by an object of unknown mass is:

$$
M_{x}\left[1-\frac{\rho_{a}}{\rho_{x t}}\right] g=K O_{2 a}
$$

where $M_{x}$ is the mass of the unknown object and $\rho_{x}$ is its density at temperature t.

Therefore:

$$
S \frac{\left[1-\frac{\rho_{0}}{\rho_{s t}}\right]}{L}=M_{x}\left(1-\frac{\rho_{0}}{\rho_{x t}}\right)
$$

Where $L$ is the ratio of balance observations:

$$
L=\frac{O_{1 \rho}-O_{o s}^{\prime}}{O_{2 s}-O_{\infty \theta}}
$$

The term, $O_{o e}^{\prime}$, is the balance no-load indication during the calibration cycle and is set to be zero and $\mathrm{O}_{0 \text { e }}$ is zero or near zero when the balance pan is empty during the weighing cycle. Furthermore, the balance response when the calibration weight is engaged, $O_{1 a}-O_{o s}^{\prime}$, is redefined as $O_{c}$ for this and all remaining applicable equations. We can now express a solution for the unknown mass, $M_{x}$ in terms of the balance observations:

$$
M_{x}=\frac{s\left[1-\frac{\rho_{a}}{\rho_{s t}}\right]}{\left[\frac{O_{c}}{O_{2 s}-O_{\infty}}\right]\left(1-\frac{\rho_{s}}{\rho_{x t}}\right)}
$$


With a knowledge of the calibration weight's mass and its density at the air temperature, $t$, from a simple weighing one can calculate the mass of an unknown object. Obviously the roles of $S$ and X can be interchanged to perform an in situ builtin mass calibration.

In calibrating the balarice, the manufacturer forces the no-load indication to be zero and when the calibration mass is engaged, adjusts it to indicate its nominal value. The ideal balance response is, of course, a straight line connecting these points, and for some balances accuracy is preserved with extrapolation beyond these bounds. Usually, balances do not respond in the ideal manner and therefore any observation not at calibrated points may require correction for nonlinearity. In the following discussion, it is assumed that the correction for nonlinearity has been applied to the balance observations for the unknown object during both the air and water weighings. The balance linearity is discussed with greater detail in [8] and is considered briefly here later in the discussion.

\section{The General Hydrostatic Weighing Equations}

It has been assumed that the air densities during the air and water weighings are different and it follows that the various temperatures, barometric pressure, and relative humidity involved may also be different. Temperature variations ensure that there will be two slightly different densities for the object during the measurement sequence. This can occur even with no lack of thermal equilibrium between the constituents during each of the weighings, since different temperatures may be encountered during air and water weighing. However, as noted earlier, it is desirab!e to have the water temperature slightly cooler than that of the surrounding air during the water weighing cycle. Special precautions [12] must be taken to protect the measurement from thi undesirable effects of this boundary condition.

The above simple weighing equations are now replaced with ones that permit variations in the ambient conditions that surround the objects during the weighings. Furthermore, the dependency of the balance calibration with respect to air density is now taken into account. In addition, it is desirable to express the object density at a reference temperature that may be different from that of the measurement. The expanded weighing equations are:

$$
S \frac{\left(1-\frac{\rho_{o s}}{\rho_{s}} Z_{1}\right]}{\left[\frac{O_{c}}{O_{2 s}-O_{o s}}\right]} g=M_{x}\left(1-\frac{\rho_{a s}}{\rho_{x t h}}\right) X g \quad \text { air weighing }
$$

Solving the above equations for the unknown density, $\rho_{x m}$ we have: 


$$
\begin{aligned}
& S \frac{\left(1-\frac{\rho_{\text {aw }}}{\rho_{s} Z_{2}}\right)}{\left(\frac{O_{c}}{O_{2 w}-O_{o w}}\right)} g=M_{x}\left(1-\frac{\rho_{w}}{\rho_{x t n}}\right) Y g \quad \text { water weighing } \\
& \rho_{x t ⿱ 一}=\left[\frac{\left(1-\frac{\rho_{s o}}{\rho_{s} Z_{1}}\right)}{\left[\frac{O_{c}}{O_{2 s}-O_{o s}}\right)} \rho_{w} Y-\frac{\left(1-\frac{\rho_{s w}}{\rho_{s} Z_{2}}\right)}{\left[\frac{O_{c}}{O_{2 w}-O_{o w}}\right)} \rho_{o s} X\right] /\left[\frac{\left(1-\frac{\rho_{s o s}}{\rho_{s} Z_{1}}\right)}{\left[\frac{O_{c}}{O_{2 s}-O_{o s}}\right)}-\frac{\left(1-\frac{\rho_{s w}}{\rho_{s} Z_{2}}\right)}{\left(\frac{O_{c}}{O_{2 w}-O_{o w}}\right)}\right]
\end{aligned}
$$

where:

$\rho_{\text {xen }}=$ Density of solid under test at $20^{\circ} \mathrm{C}$

$S=$ Mass of calibration weight and $\rho_{\mathrm{s}}$ its density at $20^{\circ} \mathrm{C}$

tn $=20^{\circ} \mathrm{C}$

The reader will note that the density of the calibration weight now appears in the solution for $\rho_{\mathrm{m}}$ whereas its mass does not.

Air Weighing

$Z_{1}=1 /\left[1+3 a\left(t_{e q}-20\right)\right]$

$X=1+3 \beta\left(t_{0}-2.0\right)$

$a=$ linear thermal expansion of $S$

$\beta=$ linear thermal expansion of object undergoing test

$t_{\infty 0}=$ air temperature

$\rho_{\infty}=$ air density

$O_{\infty}=$ the balance "zero" reading (pan empty)

$O_{c}=$ the balance indication with calibration weight engaged

$\mathrm{O}_{20}=$ balance indication when loaded with the object of interest

Note: The balance "zero reading" may not actually be 0 .

\section{Water Weighing}

$Z_{2}=1 /\left[1+3 a\left(t_{A w}-20\right)\right]$

$Y=1+3 \beta\left(t_{w}-20\right)$

$t_{w}=$ water temperature

$\rho_{w}=$ water density

$t_{\text {ow }}=$ air temperature

$\rho_{\text {ow }}=$ air density

Note: $O_{2 w}$ is approximately equal to $O_{26}$ above 
The differences in elevation between the calibration weight, the air weighing pan and the lower immersed pan require corrections for the gradient in the earths gravitational field $[2,10]$. This correction is approximately 200 micrograms per kilogram per meter. In the case of the balance used at NIST, the calibration weight and the air weighing pan are at the same elevation and the (lower) water weighing observations are adjusted to that elevation.

\section{Linearity Test and Correction}

The terms above, $O_{26}$ and $O_{2 w}$ are assumed to have been corrected for any nonlinear balance response. We obtained the corrections by observing the balance response at $25 \%, 75 \%$ and $100 \%$ of capacity. The balance is calibrated with a $100-\mathrm{g}$ weight (50\% of capacity) and its capacity is $200 \mathrm{~g}$; therefore, an additional $100 \mathrm{~g}$ and $50 \mathrm{-g}$ weight is required for the test. As noted earlier, the balance calibration forces a panempty indication of 0.0000 and the 100-g indication to be 100.0000 ; these points are given and not observed. However, it is prudent to immediately check the calibration by reweighing the calibration weight or its replica. This provides assurance that an error-free calibration occurred. Repeat the procedure as necessary as some balances require several cycles to obtain a stable calibration.

A detailed discussion of the balance linearity test and corrections is given in [8]. The linearity corrections can be avoided by root-sum-squaring the balance nonlinearity with its precision when estimating the uncertainty of the density measurement.

\section{ANALYSIS}

The method describeJ by $\mathrm{Ku}$ [13] has been used to propagate errors in the functional relationship, $f\left(X_{1}, X_{2}, \ldots, X_{n}\right)$, of the uncorrelated variables $X_{1}, X_{2}, \ldots, X_{n}$. Tables 1 and 2 present for each variable its value, the estimated standard deviation and an evaluation of the partial derivatives. At the bottom of each table is the estimated combined standard deviation for the function as given by the following relationship:

$$
\left(S D_{\rho_{x}}\right)=\left[\sum_{i=1}^{n}\left[\frac{\partial f}{\partial X_{i}}\right]^{2}\left(S D_{i}\right)^{2}\right]^{\frac{1}{2}}
$$

The measurement uncertainty for the density of the silicon crystal is the root-sumsquare of the estimated effects listed in the tables. The effect for each variable in the table is calculated from the square root of both sides of the above equation. For convenience to the reader we list the partial derivatives here and will use them to perform a sample calculation later. We have chosen to propagate the errors through the simple form of equation (3) rather than the more complex form of equation (12). The resulting calculated uncertainty from the following equations are nearly the same.

One important parameter in the error analysis is the balance reproducibilty as measured by the standard deviation. The balance used here, like many electronic 


$$
\begin{gathered}
\frac{\partial \rho_{x}}{\partial O_{w L}}=\frac{-O_{A L}\left(\rho_{a}-\rho_{w}\right)}{\left(O_{w L}-O_{A L}\right)^{2}} \\
\frac{\partial \rho_{x}}{\partial O_{A L}}=\frac{O_{w L}\left(\rho_{a}-\rho_{w}\right)}{\left(O_{w L}-O_{A L}\right)^{2}} \\
\frac{\partial \rho_{x}}{\partial \rho_{a}}=\frac{O_{w L}}{O_{w l}-O_{A L}} \\
\frac{\partial \rho_{x}}{\partial \rho_{w}}=\frac{-O_{A L}}{O_{w l}-O_{A L}}
\end{gathered}
$$

balances, performs better when lightly loaded. Its standard deviation was found to be $49 \mu \mathrm{g}$ from 0 to $100 \mathrm{~g}$ and $118 \mu \mathrm{g}$ upward to $200 \mathrm{~g}$. These standard deviations are combined in quadrature with the standard deviation of the linearity correction. At the 200-g level of the air weighings the combined standard deviation is $138 \mu \mathrm{g}$, while water weighings near $100 \mathrm{~g}$ are nearly free of nonlinearity and the standard deviation remains $49 \mu \mathrm{g}$. As previously noted, the balance weighings were repeated 6 times, which is reflected in Table 1 . It is noteworthy that the balance calibration reproducabilty ( $49 \mu \mathrm{g}$ ) is not improved by repeated calibration cycles and therefore is only performed once. This standard deviation cannot be obtained explicitly but from the nature of digital circuits it is known to be less than $1 / 2$ count, i.e. $50 \mu \mathrm{g}$, and the value $(49 \mu \mathrm{g})$ determined by repeated weighings at the $100-\mathrm{g}$ level was used here. Furthermore, the balance indications are labeled as balance units. Clearly if the mass of the built-in weight is a known mass then the observations would be in SI units. It is only necessary to know the mass of the built-in weight if one wishes to make a mass measurement. To recapitulate, to determine the uncertainty applicable to a density measurement made by the method described here, one only requires knowledge of the balance standard deviation and its lack of linearity, if any. 
TABLE 1

\begin{tabular}{||l|l|l|l|l||}
\hline variable & Value & SD & Partial & effect \\
\hline $\begin{array}{l}\rho_{\mathrm{a}} \\
\text { (air den.) }\end{array}$ & $\begin{array}{l}0.001 \\
2 \\
\mathrm{~g} / \mathrm{cm}^{3}\end{array}$ & $\begin{array}{c}0.0000003 \\
\mathrm{~g} / \mathrm{cm}^{3}\end{array}$ & -1.352942 & $\begin{array}{c}0.0000004 \\
\mathrm{~g} / \mathrm{cm}^{3}\end{array}$ \\
\hline $\begin{array}{l}\rho_{\mathrm{w}} \\
\left(\mathrm{H}_{2} \mathrm{O} \text { den.) }\right.\end{array}$ & $\begin{array}{l}0.997 \\
\mathrm{~g} / \mathrm{cm}^{3}\end{array}$ & $\begin{array}{c}0.0000017 \\
\mathrm{~g} / \mathrm{cm}^{3}\end{array}$ & 2.352941 & $\begin{array}{c}0.0000040 \\
\mathrm{~g} / \mathrm{cm}^{3}\end{array}$ \\
\hline $\begin{array}{l}\mathrm{O}_{\text {aL }} \\
\text { (bal units) }\end{array}$ & 200 & $0.000042 / \sqrt{6}$ & -0.015856 & $\begin{array}{c}0.0000003 \\
\mathrm{~g} / \mathrm{cm}^{3}\end{array}$ \\
\hline $\begin{array}{l}\mathrm{O}_{\mathrm{m}} \\
\text { (bal units) }\end{array}$ & 85 & $0.000138 / \sqrt{6}$ & 0.027643 & $\begin{array}{c}0.0000016 \\
\mathrm{~g} / \mathrm{cm}^{3}\end{array}$ \\
\hline \multicolumn{2}{|l|}{} & & $\mathrm{RSS}=$ & $\begin{array}{c}0.000004 \\
\mathrm{~g} / \mathrm{cm}^{3}\end{array}$ \\
\hline
\end{tabular}

\section{BALANCE SELECTION}

Obviously we need a balance with a 200-g capacity for the silicon crystal density determination. If we examine the effect of the balance water weighing abservation, $\mathrm{O}_{m}$, for Table 1; we find that it is the largest for all the variables except the density of water. We cannot improve our information regarding the density of water, but a better performing balance can improve the measurements. However, the measurement error is approaching the limitation imposed by the water density and if the improvement were not required, doing so would not be cost effective.

Consider a hypothetical measurement of the density of a 1-kilogram stainless steel mass standard. There are many balances available; the best (i.e., smallest standard deviation) cost about 24 times the least precise instrument. We tentatively have selected a balance that cost one-twelfth as much as the most expensive one. Based on the manufacturer's specification we can construct a table like the one above and see if the cheaper balance will be satisfactory. The pertinent specifications are:

$$
\begin{gathered}
S D=0.001 \mathrm{~g} \\
\text { linearity error }=0.003 \mathrm{~g} \text { or less }
\end{gathered}
$$

The goal here is to determine the density of the kilogram to 1 part in 100,000 . 
TABLE 2

\begin{tabular}{||l|l|l|l|l||}
\hline variable & Value & SD & Partial & effect \\
\hline $\begin{array}{l}\rho_{\text {air den.) }} \\
\text { (air }\end{array}$ & $\begin{array}{l}0.001 \\
2 \\
\mathrm{~g} / \mathrm{cm}^{3}\end{array}$ & $\begin{array}{c}0.0000003 \\
\mathrm{~g} / \mathrm{cm}^{3}\end{array}$ & -7.0 & $\begin{array}{c}0.000002 \\
\mathrm{~g} / \mathrm{cm}^{3}\end{array}$ \\
\hline $\begin{array}{l}\rho_{\mathrm{w}} \\
\left(\mathrm{H}_{2} \mathrm{O} \text { den.) }\right.\end{array}$ & $\begin{array}{l}0.997 \\
4 \\
\mathrm{~g} / \mathrm{cm}^{3}\end{array}$ & $\begin{array}{c}0.0000017 \\
\mathrm{~g} / \mathrm{cm}^{3}\end{array}$ & 8.0 & $\begin{array}{c}0.000014 \\
\mathrm{~g} / \mathrm{cm}^{3}\end{array}$ \\
\hline $\begin{array}{l}\mathrm{O}_{\text {a }} \\
\text { (bal units) }\end{array}$ & $1000 \mathrm{~g}$ & $0.001 \mathrm{~g}$ & -.0639104 & $\begin{array}{c}0.000064 \\
\mathrm{~g} / \mathrm{cm}^{3}\end{array}$ \\
\hline $\begin{array}{l}\mathrm{O}_{\text {aw }} \\
\text { (bal units) }\end{array}$ & $875 \mathrm{~g}$ & $0.0032 \mathrm{~g}$ & -.0557872 & $\begin{array}{c}0.000178 \\
\mathrm{~g} / \mathrm{cm}^{3}\end{array}$ \\
\hline \multicolumn{2}{|l|}{} & \multicolumn{2}{|c|}{$\mathrm{RSS}=$} & $\begin{array}{c}0.00019 \\
\mathrm{~g} / \mathrm{cm}^{3}\end{array}$ \\
\hline
\end{tabular}

We anticipate that we can measure the density of a kilogram of stainless steel, 8 $\mathrm{g} / \mathrm{cm}^{3}$, with an error of $0.00019 \mathrm{~g} / \mathrm{cm}^{3}$ or about 1 part in 40,000 , and would not achieve our goal. If on the other hand we were able to correct the balance.indications for the nonlinear response and record 9 water weighing observations, we could achieve a standard deviation of about $0.001 \mathrm{~g}$, comparable to that of the air weighing. Because our balarice span is calibrated at $1000 \mathrm{~g}$ there is no nonlinearity correction to apply to the air weighing observations. With small additional effort we could achieve an error of $0.0000558 \mathrm{~g} / \mathrm{cm}^{3}$ for the water weighing and an RSS of slightly better than 1 part in 100,000. We conclude that the selected balance will be adequate for the measurement goal provided the user applies the linearity correction and performs 9 water weighing cycles. The reader should note that table 1 and table 2 both have the same standard deviations for the air density and water density. Although we cannot improve these parameters very much, we could make them much worse, depending on how well we measure the temperatures, relative humidity and barometric pressure. See reference [7] for a similar treatment of these parameters.

\section{DATA RESULTS}

Six independent determinations of the density of a 200-g silicon crystal were made [7]. The crystal density is known to $2.25 \mathrm{ppm}$ [3]. The data made using the electronic force balance and the method described here resulted in a standard deviation of $2 \mathrm{ppm}$ with an offset of $2.4 \mathrm{ppm}$ from the more accurate interferometric results described in [3]. 


\section{CONCLUSIONS}

We believe our investigations of the testing and use of the electronic balance support the contention that very respectable measurements at the parts per million level can be achieved. It is noteworthy that when the balance is used properly the need for well-calibrated laboratory weight sets is eliminated. Most users would be well served by obtaining both a mass value and a density determination for the balance calibration weight from an appropriate calibration laboratory. The needs of many users would certainly be satisfied by accepting the value and tolerance assigned by a reputable balance maker.

We did not cover all of the common uses of balances. There are simple applications such as the tolerance testing of weights for regulatory use, i.e., weights and measures, to which these techniques can be adopted. It appears to us that many modern electronic balances perform so well that it might be beyond the ability of many laboratories to adequately test and calibrate them. This could well be a problem in the future where some applications, requiring certification, are limited by the ability of the certifying agency.

\section{APPENDIX 1 - LIQUID DENSITY BY HYDROSTATIC WEIGHING}

An examination of eq. (12) reveals the possibility of determining the water density, or the density of other liquids, with prior knowledge of the solid object density. Relabeling the terms $\rho_{w}$ as $\rho_{t}$ and $\rho_{x}$ as $\rho_{y}$ and rearranging terms, the density of an unknown liquid by hydrostatic weighing is:

$$
\rho_{L B t}=\left[\rho_{\text {Sitn }}\left[\frac{\left(1-\frac{\rho_{a s}}{\rho_{s} Z_{1}}\right)}{\left[\frac{O_{c}}{O_{2 s}-O_{o s}}\right]}-\frac{\left(1-\frac{\rho_{a w}}{\rho_{s} Z_{2}}\right)}{\left.f \frac{O_{c}}{O_{2 w}-O_{o w}}\right]}\right]+\rho_{a s} X \frac{\left(1-\frac{\rho_{a L}}{\rho_{s} Z_{2}}\right)}{\left[\frac{O_{c}}{O_{2 w}-O_{o w}}\right]}\right] / Y \frac{\left(1 \frac{\rho_{a s}}{\rho_{s} Z_{1}}\right)}{\left[\frac{O_{c}}{O_{2 s}-O_{o s}}\right)}
$$

where:

$\rho_{L B}=$ Liquid density under test at the bath temperature, Bt.

$\rho_{\text {ston }}=$ Solid object density standard normalized at $25^{\circ} \mathrm{C}$.

\section{APPENDIX 2 - GLASSWARE CALIBRATION}

Flasks, burettes and pipetes are usually calibrated by gravimetric means. A simplified equation is offered here for the calibration of general use glassware. The capacity, $C_{t}$, is: 


$$
C_{t}=S \frac{\left(1-\frac{\rho_{s}}{\rho_{s}}\right)\left(\frac{O_{F}-O_{E}}{O_{c}}\right)}{\rho_{w}-\rho_{a}}
$$

Where:

$t=$ water temperature in degrees Celsius

$\rho_{0}=$ average air density of the weighing cycles

$\rho_{w}=$ water density

$\rho_{s}=$ calibration weight density at room temperature

$O_{E}=$ empty flask balance indication

$O_{F}=$ flask plus water balance indication

In the above equation it is assumed that the balance has been zeroed before the empty and full weighings and the flask capacity is at the temperature of the water. The nominal value of the built-in calibration mass, $S$, is usually adjusted to be accurate within the least significant digit displayed by the balance and may not need additional calibration for this application. It has been assumed that the weight is made from a material with a density near $8.0 \mathrm{~g} / \mathrm{cm}^{3}$ and has been adjusted to the " 8.0 apparent mass scale."

\section{REFERENCES}

[1] Bowman, H.A.; Gallagher, W.; Schoonover, R.M., "The Development of a Working Density Standard," Instrument Society of America, 20th Annual ISA Conference and Exhibit, Preprint No. 14.8-4.65, Los Angeles, CA (1965).

[2] Bowman, H.A.; Schoonover, R.M., "Procedure for High Precision Density Determinations by Hydrostatic. Weighing," J. Res. NBS 71C: 179-198 (1967).

[3] Bowman, H.A.; Schoonover, R.M.; Carroll, C.L., "A Density Scale Based on Solid Objects,: J. Res. NBS 78A: 13-40 (1974).

[4] Bowman, H.A.; Schoonover, R.M.; Carroll, C.L., "The Utilization of Solid Objects as Reference Standards in Density Measurements," Metrologia 10, 117-121 (1974).

[5] Bowman, H.A.; Schoonover, R.M.; Carroll, C.L., "Reevaluation of the Densities of the Four NBS Silicon Crystal Standards," NBSIR 75-768, Final report prepared for Mechanics Division, Institute for Basic Standards (1975).

[6] Schoonover, R.M., "A Look at the Electronic Analytical Balance," Anal. Chem. 973A-980A (1982).

[7] Schoonover, R.M; Jones, F.E, "Examination of Parameters That Can Cause Errors in Mass Determination," Measuement Science Conference 94, Pasadena California 
[8] Schoonover,R.M, et al, "The Electronic Balance and Some Gravimetric Appilcations,"ISA 1993 Proceedings of the $39^{\text {th }}$ International Instrumentation Symposium.

[9] Davis, R.S.; "Equation for the Determination of the Density of Moist Air (1981/91)" Metrologia (1992), 29.

[10] Kell, G.S.; "Density, Thermal Expansivity, and Compressibility of Liquid Water from 0 to $150{ }^{\circ} \mathrm{C}$ : Correlations and Tables for Atmospheric Pressure and Saturation Reviewed and Expressed on 1968 Temperature Scale" Journal of Chemical Engineering Data, Vol 20, No. 1, (1975).

[11] Magnum, B.W.; Furakawa, G.T., "Guidlines for realizing the International Temperature Scale of 1990 (ITS-90)," NIST Technical Note 1265.

[12] Schoonover, R.M.; Taylor, J.E., "Some Recent Developements at NBS in Mass Measurements," IEEE Instrumentation and Measurement Conference, Boulder, CO (1986)

[13] Ku, H.S.; "Statistical Concepts in Metrology" Handbook of Industrial Metrology, Chapter 3, American Society of Tool and Manufacturing Engineers, Prentice-Hall, NY, (1967). 

